\title{
Interaction analysis of lipid accumulation product and family history of diabetes on impaired fasting glucose and diabetes risk in population with normotension in Eastern China: a community-based cross-sectional survey
}

\section{Li Shu ( $\nabla$ shuli_ay@126.com )}

Bengbu Medical College https://orcid.org/0000-0003-2868-0071

Yingying Zhao

Anhui Provincial CDC: Anhui Provincial Center for Disease Control and Prevention

\section{Yanqi Shen}

Bengbu Medical College

Linlin Jia

Bengbu Medical College

Jiaye Zhang

Bengbu Medical College

\section{Research Article}

Keywords: Interaction, LAP, IFG, Diabetes, Normotension

Posted Date: January 28th, 2022

DOI: https://doi.org/10.21203/rs.3.rs-226460/v2

License: (c) (1) This work is licensed under a Creative Commons Attribution 4.0 International License. Read Full License 


\section{Abstract}

Background: Lipid accumulation product (LAP) is considered to be a new convenient useful indicator to assess the visceral fat. Therefore, we aimed to evaluate the risk factors of impaired fasting glucose (IFG) and diabetes, and explore the possible interacting influences of LAP with other factors on the risk of IFG and diabetes among Chinese normotension adults.

Methods: A multistage stratified cluster sampling method was conducted to select urban residents in Bengbu, China. For each eligible participant, data on questionnaire survey, anthropometric measurements and laboratory tests were obtained. The effects of body mass index (BMI), waist circumference (WC), waist to height ratio (WHtR) and LAP for predicting IFG and diabetes were performed by multiple logistic regressions and receiver operating characteristic (ROC) analyses. The interaction effects were evaluated by relative excess risk of interaction (RERI), attributable proportion due to interaction (AP) and synergy index (SI).

Results: 6467 normotension subjects ( 2695 men and 3772 women) were enrolled in our study, the prevalence of IFG and diabetes were $9.37 \%$ and $14.33 \%$, respectively. When assessed using ROC curve analysis, LAP exhibited higher diagnostic accuracy for identifying IFG and diabetes than BMI, the area under the AUC curve was 0.650 (95\% Cl: 0.637 to 0.662). After adjustment for age, sex, educational level and other confounding factors, multivariate logistic regression analyses indicated that subjects with the fourth quartile of LAP were more likely to develop IFG (adjusted OR: 2.735, 95\% Cl: 1.794-4.170) and diabetes (adjusted OR: 1.815, 95\% Cl: 1.297-2.541) than those with the first quartile. A significant interaction between LAP and family history of diabetes was observed in participants (RERI=1.538, 95\% Cl: 0.167 to $3.612 ; \mathrm{AP}=0.375,95 \% \mathrm{Cl}: 0.118$ to $0.631 ; \mathrm{SI}=1.980,95 \% \mathrm{Cl}: 1.206$ to 3.251$)$. However, a significant interaction between LAP and abdominal obesity was indicated by the value of RERI $(1.492,95 \% \mathrm{Cl}: 0.087$ to 3.723$)$ and $\mathrm{AP}(0.413,95 \% \mathrm{Cl}: 0.014$ to 0.756$)$, but not the value of SI $(1.824,95 \% \mathrm{Cl}: 0.873$ to 3.526$)$.

Conclusion: Our results demonstrated that there might be synergistic effect between LAP and family history of diabetes on the risk of IFG and diabetes.

\section{Background}

Type 2 diabetes is considered to be one of the most prevalent noncommunicable disease worldwide, the number of adults with diabetes worldwide was estimated to be 366 million in 2011 and will reach 552 million by 2030 [1-2]. The etiology of diabetes is not well defined, it is assumed to be a polygenic disorder involving interactions between environmental and genetic risk factors [3-4]. Meanwhile, most patients often undiagnosed for many years while the patient progresses symptom-free through the earlier stage of diabetes known as impaired fasting glucose (IFG), IFG is a manifestation of glucose metabolism disorder in the early period [5]. A report in China demonstrated that nearly 148.2 million adults were suffering from IFG [6], it is more likely for IFG patients to further progress to diabetes. A large amount evidence showed that IFG and diabetes were closely related to cardiovascular events [7-9], a cohort 
study carried out in rural areas of China showed that the cumulative incidence of hypertension was substantially higher in IFG and diabetes groups while compared with normal blood glucose group [10]. Hence, it is necessary to search the risk factors and analyze how synergisms between them to influence the development of IFG and diabetes.

Body mass index (BMI) is the recommended indicator to assess and diagnose obesity [11-12], but there is increasing evidence indicating that BMI is not the ideal body fat index [13], it has limitation to differentiate fat and muscle mass and can not reflect central obesity. A research conducted in America showed that $33 \%$ of elderly adults at a normal weight defined by BMI have pre-diabetes [14]. Schulze et al [15] reported that WC and WHtR instead of BMI considering their positive correlations with IFG and diabetes, however, WC and WHtR did not show the excess body fat in circulating blood [16]. Therefore, it is urgently to explore other valuable diabetes predicators to enhance screening accuracy.

The lipid accumulation product (LAP) is a powerful parameter based on WC and serum triglycerides (TG) for predicting diabetes in adults by Kahn et al [17-18]. It is an emerging indicator that indirectly expresses central fat accumulation and has been developed to be independently associated with impaired fasting glucose, type 2 diabetes, coronary heart disease and metabolic syndrome [19-21]. Several population-based studies have emphasized the association between LAP and metabolic diseases in different countries [22-24], but there are few studies to investigate the association between LAP and diabetes in China. Anhui, a developing province in the center of China, has experienced rapid economic development. At the same time, its residents have experienced huge lifestyle changes, such as high-fat diet, reduced physical activity and long-term sedentary work, all of which are regarded as major risk factors for diabetes, thus, the applicability of LAP in predicting IFG and diabetes in Anhui province is worth studying.

In the last few decades, it has been established that people with a family history of diabetes are at a high risk for developing diabetes [25-26], however, there were disagreements on whether or not family history has a significant impact on diabetes progress [27-28]. A family history of diabetes is considered to be an indicator of genetic susceptibility, and people with a family history of diabetes have a significantly higher risk than others. In addition, as IFG and diabetes are polygenic inheritance patterns, the joint influence of risk factors may aggravate the disease [29], but there are few studies on the interaction between family history of diabetes and other risk factors. Meanwhile, hypertension is also a relatively independent risk factor for diabetes, so we performed a cross-sectional study in a large-scale population without hypertension patients to evaluate the interaction effects between family history of diabetes and LAP on IFG and diabetes, and to provide new initiatives for the prevention of IFG and diabetes.

In this study, we aimed to (1) analyzing the association between LAP and risk of IFG and diabetes in Bengbu city, (2) comparing the predict abilities of BMI, WC, WHtR and LAP, (3) assessing the possible interactive effects between LAP and family history on IFG and diabetes risk.

\section{Methods}




\section{Study population}

A cross-sectional survey based on community health management was conducted in the Bengbu city of Anhui province in center China, from July to November 2018. The study participants whose age $\geq 45$ years old were selected by a multistage and stratified random sampling method from eleven communities. Residents were selected by community health centers who lived in the selected communities for at least 6 months and willing to cooperate with this project. The following exclusion criteria were as applied: 1 ) had no ability to communicate with investigators; 2 ) disagreed to participate in this survey; 3 ) did not complete the whole survey. A total of 9477 individuals were enrolled in our study, 338 participants who lacked demographic data, anthropometric tests and laboratory examinations were excluded. Meanwhile, 2672 hypertension residents were excluded to select for the normotension individuals. Finally, 6467 residents who had complete data were included in our analysis. The included individuals and excluded individuals had no statistically significant differences in age and sex. Informed written consent was obtained from all participants. The study was supported by Bengbu Health Board and approved by the Ethics Committee of Bengbu Medical College. The procedure of this survey is in accordance with the principles of the 1983 Declaration of Helsinki.

\section{Questionnaire survey}

All subjects were interviewed by trained interviewers by a self-designed questionnaire to collect information on age, sex, educational level, marital status, smoking, drinking, family history of diabetes, physical activity. Educational level was categorized as "middle school graduate or lower" and "high school graduate or higher". Marital status was classified as "currently married" and "currently not married". Smoking and drinking were defined as "never", "current (smoking or drinking regularly in the recent half year)" or "ever (quit smoking or drinking for more than half a year)". For family history, we defined it as one parent or both parents having diabetes. Physical activity was classified as "sufficient activity (exercised more than $150 \mathrm{~min} /$ week)" and "insufficient activity (exercised less than $150 \mathrm{~min} /$ week)"[30].

\section{Anthropometric tests and laboratory examinations}

Height and weight were measured with the participants to take off their shoes and wear lightweight clothing by trained investigators using calibrated weighing scales. WC was measured at the level of $1 \mathrm{~cm}$ above the navel using an un-stretched tape measure. Systolic blood pressure (SBP) and diastolic blood pressure (DBP) were measured with participants in a sitting position, using a corrected mercury sphygmomanometer in the right arm. Three measurements of SBP and DBP were required for each subject after a 10 minute rest, and the subject's BP was calculated as the average of the three measurements. 
Blood samples were collected in the morning after an overnight fasting for more than 8 hours from the subjects, fasting plasma glucose (FPG), total cholesterol (TC) and triglycerides (TG) were examined subsequently.

\section{Definitions}

1. BMI was calculated as weight in kilograms divided by the square of height in meters, $\mathrm{BMI} \geq 28$ was defined as general obesity[31].

2. Abdominal obesity was defined as $W C \geq 90 \mathrm{~cm}$ for men and $W C \geq 85 \mathrm{~cm}$ for women [32].

3. WHtR was calculated as WC $(\mathrm{cm})$ divided by the height $(\mathrm{cm})$ [33].

4. Hypertension was defined as SBP $\geq 140 \mathrm{mmHg}$ and/or DBP $\geq 90 \mathrm{mmHg}$ and/or with a history of antihypertensive medications [34].

5. Diabetes was diagnosed as FPG $\geq 7.0 \mathrm{mmol} / \mathrm{L}$ and/or use of hypoglycemic drugs within 2 weeks of enrollment. IFG was defined as $6.1 \mathrm{mmol} / \mathrm{L} \leq \mathrm{FPG}<7.0 \mathrm{mmol} / \mathrm{L}$ [35].

6. LAP was calculated as [WC $(\mathrm{cm})-65] \times[\mathrm{TG}(\mathrm{mmol} / \mathrm{L})]$ for males and $[\mathrm{WC}(\mathrm{cm})-58] \times[\mathrm{TG}(\mathrm{mmol} / \mathrm{L})]$ for females [18].

\section{Statistics}

The data was organized in the EpiData 3.1 software using double entry approach, an all statistical analyses were performed with IBM SPSS Statistics ver. 22.0 (IBM Co., Armonk, NY, USA) software. Firstly, data was presented as the mean \pm standard deviation for continuous variable and percentage for categorical variable, the differences in continuous or categorical variable between NFG, IFG and diabetes groups were compared by One-way ANOVA test or Chi-squared test. Furthermore, LAP was divided into four groups $\left(Q_{1}, Q_{2}, Q_{3}\right.$ and $\left.Q_{4}\right)$ by quartiles, multivariate logistic regression was applied to evaluate the risk factors for IFG and diabetes, followed by the calculation of odds ratio (OR) with corresponding $95 \%$ confidence interval $(95 \% \mathrm{Cl})$. Thirdly, the receiver operating characteristic $(\mathrm{ROC})$ analysis was determined by MedCalc Version 18 (DEMO) (MedCalc Software bvba, Ostend, Belgiumm) software, to identify the superior obesity index and the best cut-off value of LAP to predict IFG and diabetes risk. The area under the ROC curves (AUC) of BMI, WC, WHtR and LAP were calculated, and then compared by non-parametric significance test (statistics of $Z$ ). Finally, the interaction effects were evaluated by relative excess risk of interaction ( $\left.\mathrm{RERI}=\mathrm{OR}_{11}-\mathrm{OR}_{10}-\mathrm{OR}_{01}+1\right)$, attributable proportion due to interaction ( $\mathrm{AP}=\left[\mathrm{OR}_{11^{-}}-\mathrm{OR}_{10^{-}}\right.$ $\left.\left.\mathrm{OR}_{01}+1\right] / \mathrm{OR}_{11}\right)$ and synergy index $\left(\mathrm{SI}=\left[\mathrm{OR}_{11}-1\right] /\left[\mathrm{OR}_{01}-1\right]+\left[\mathrm{OR}_{10}-1\right]\right)$. The excel table designed by Andersson et al were used to calculate all of these indicators $[30,36]$. If the $95 \% \mathrm{Cl}$ of RERI and AP do not include 0 , the $95 \% \mathrm{Cl}$ of SI do not include 1 , the interactions are statistically significant. The $P$-value $<0.05$ (twotailed) was set for statistical significance. 


\section{Results}

Table 1 shows the demographic characteristics of the 6467 participants (2695 men and 3772 women) with normotension stratified by their FPG levels. The total prevalence of NFG, IFG and diabetes was $76.30 \%, 9.37 \%$ and $14.33 \%$, respectively. The mean age for NFG, IFG and diabetes groups were $62.56 \pm 6.06,62.72 \pm 5.97$ and $62.47 \pm 5.74$ years old, respectively. Significant difference was presented in family history of diabetes $(p<0.001)$ between NFG, IFG and diabetes groups. Anthropometric measurements found significant differences in BMI $(p<0.001)$, WC $(p<0.001)$, WHtR $(p<0.001), \mathrm{LAP}$ $(p<0.001)$, general obesity $(p<0.001)$ and abdominal obesity $(p<0.001)$ between the groups. Laboratory examinations found significant differences in systolic blood pressure $(p<0.001)$, fasting plasma glucose $(p<0.001)$ and triglyceride $(p<0.001)$ between the groups. 
Table 1

Basic characteristics of the participants

\begin{tabular}{|c|c|c|c|c|c|}
\hline Variables & $\begin{array}{l}\text { NFG } \\
(\mathrm{N}=4934)\end{array}$ & $\begin{array}{l}\text { IFG } \\
(\mathrm{N}=606)\end{array}$ & $\begin{array}{l}\text { Diabetes } \\
(\mathrm{N}=927)\end{array}$ & $F / x^{2}$ & $P$ \\
\hline Age (years) & $62.56 \pm 6.06$ & $62.72 \pm 5.97$ & $62.47 \pm 5.74$ & 0.327 & 0.721 \\
\hline $\operatorname{Sex}[n(\%)]$ & & & & 1.903 & 0.386 \\
\hline Male & $2043(41.4)$ & $247(40.8)$ & $405(43.7)$ & & \\
\hline Female & $2891(58.6)$ & $359(59.2)$ & $522(56.3)$ & & \\
\hline Education level [n(\%)] & & & & 0.305 & 0.859 \\
\hline $\begin{array}{l}\text { Middle school graduate or } \\
\text { lower }\end{array}$ & $4259(86.3)$ & $527(87.0)$ & $797(86.0)$ & & \\
\hline High school graduate or higher & $675(13.7)$ & $79(13.0)$ & $130(14.0)$ & & \\
\hline Marital status [n(\%)] & & & & 0.115 & 0.944 \\
\hline Currently married & 4354(88.2) & $536(88.4)$ & $815(87.9)$ & & \\
\hline Currently not married & $580(11.8)$ & $70(11.6)$ & $112(12.1)$ & & \\
\hline Smoking $[n(\%)]$ & $404(8.2)$ & $48(7.9)$ & $79(8.5)$ & 0.190 & 0.909 \\
\hline Drinking [n(\%)] & $521(10.6)$ & $57(9.4)$ & $82(8.8)$ & 2.967 & 0.227 \\
\hline BMI $\left(\mathrm{kg} / \mathrm{m}^{2}\right)$ & $24.21 \pm 3.14$ & $25.18 \pm 3.22$ & $25.22 \pm 3.29$ & 56.545 & 0.000 \\
\hline WC (cm) & $84.63 \pm 9.30$ & $87.08 \pm 9.76$ & $87.61 \pm 9.82$ & 51.054 & 0.000 \\
\hline WHtR & $0.53 \pm 0.06$ & $0.54 \pm 0.06$ & $0.54 \pm 0.06$ & 39.272 & 0.000 \\
\hline General obesity [n(\%)] & $579(11.7)$ & 104(17.2) & 165(17.8) & 34.812 & 0.000 \\
\hline Abdominal obesity [n(\%)] & $1887(38.2)$ & $302(49.8)$ & $477(51.5)$ & 76.675 & 0.000 \\
\hline $\begin{array}{l}\text { Systolic blood pressure } \\
(\mathrm{mmHg})\end{array}$ & $124.98 \pm 9.33$ & $127.16 \pm 8.21$ & $126.64 \pm 8.63$ & 24.969 & 0.000 \\
\hline $\begin{array}{l}\text { Diastolic blood pressure } \\
(\mathrm{mmHg})\end{array}$ & $76.06 \pm 7.28$ & $76.62 \pm 6.96$ & $76.26 \pm 7.27$ & 1.795 & 0.166 \\
\hline $\begin{array}{l}\text { Fasting plasma glucose } \\
(\mathrm{mmol} / \mathrm{L})\end{array}$ & $4.94 \pm 0.56$ & $6.49 \pm 0.27$ & $9.25 \pm 2.35$ & 7187.339 & 0.000 \\
\hline Total cholesterol (mmol/L) & $4.88 \pm 1.15$ & $4.97 \pm 1.08$ & $4.90 \pm 1.29$ & 1.877 & 0.153 \\
\hline Triglyceride (mmol/L) & $1.44 \pm 1.03$ & $1.63 \pm 1.12$ & $1.80 \pm 1.43$ & 46.717 & 0.000 \\
\hline $\begin{array}{l}\text { Family history of diabetes } \\
{[\mathrm{n}(\%)]}\end{array}$ & 708(14.3) & $142(23.4)$ & 268(28.9) & 133.369 & 0.000 \\
\hline
\end{tabular}




\begin{tabular}{|llllll|}
\hline Variables & NFG & IFG & Diabetes & $F / \chi^{2}$ & $P$ \\
& $(\mathrm{~N}=4934)$ & $(\mathrm{N}=606)$ & $(\mathrm{N}=927)$ & & \\
\hline LAP & $35.17 \pm 31.49$ & $43.68 \pm 38.94$ & $48.83 \pm 44.79$ & 70.659 & $\mathbf{0 . 0 0 0}$ \\
\hline
\end{tabular}

As for LAP, we divided it into four groups by quartile to investigate the relationship between LAP and cardiovascular risk factors, the results showed that variables such as BMI $(p<0.001), \mathrm{WC}(p<0.001), \mathrm{WHtR}$ $(p<0.001), \mathrm{FPG}(p<0.001), \mathrm{TC}(p<0.001), \mathrm{TG}(p<0.001)$ and so on were relatively elevated in participants with higher LAP quartiles (Table 2). As shown in Figure 1, the prevalence of IFG and diabetes gradually increased across LAP quartiles ( $P$ for trend $<0.001$ for both groups). 
Table 2

Comparisons of cardiovascular risk factors among four quartiles of LAP

\begin{tabular}{|c|c|c|c|c|c|c|}
\hline \multirow[t]{2}{*}{ Variables } & \multicolumn{4}{|l|}{ LAP } & \multirow[t]{2}{*}{$F / X^{2}$} & \multirow[t]{2}{*}{$P$} \\
\hline & $Q_{1}(<18.17)$ & $\begin{array}{l}\mathrm{Q}_{2}(18.17- \\
28.79)\end{array}$ & $\begin{array}{l}Q_{3}(28.80- \\
46.19)\end{array}$ & $Q_{4}(\geq 46.20)$ & & \\
\hline$n$ & 1616 & 1601 & 1622 & 1628 & - & - \\
\hline Age (years) & $63.28 \pm 6.41$ & $62.57 \pm 6.05$ & $62.40 \pm 5.89$ & $62.03 \pm 5.58$ & 12.480 & 0.000 \\
\hline \multicolumn{5}{|l|}{$\operatorname{Sex}[n(\%)]$} & \multirow[t]{3}{*}{255.088} & \multirow[t]{2}{*}{0.000} \\
\hline Male & $918(56.8)$ & $680(42.5)$ & $608(37.5)$ & $489(30.0)$ & & \\
\hline Female & $698(43.2)$ & $921(57.5)$ & $1014(62.5)$ & $1139(70.0)$ & & \\
\hline Smoking [n(\%)] & $170(10.5)$ & 111(6.9) & 123(7.6) & 127(7.8) & 16.110 & 0.001 \\
\hline Drinking [n(\%)] & 215(13.3) & 154(9.6) & 164(10.1) & 127(7.8) & 27.823 & 0.000 \\
\hline $\mathrm{BMI}\left(\mathrm{kg} / \mathrm{m}^{2}\right)$ & $22.38 \pm 2.72$ & $23.96 \pm 2.71$ & $25.09 \pm 2.84$ & $26.34 \pm 3.09$ & 568.279 & 0.000 \\
\hline WC (cm) & $77.91 \pm 6.20$ & $83.38 \pm 7.18$ & $87.41 \pm 7.78$ & $92.38 \pm 9.83$ & 985.462 & 0.000 \\
\hline WHtR & $0.48 \pm 0.04$ & $0.52 \pm 0.04$ & $0.54 \pm 0.05$ & $0.58 \pm 0.06$ & 1096.950 & 0.000 \\
\hline $\begin{array}{l}\text { General obesity } \\
\text { [n(\%)] }\end{array}$ & $46(2.8)$ & 119(7.4) & 238(14.7) & $445(27.3)$ & 487.286 & 0.000 \\
\hline $\begin{array}{l}\text { Abdominal } \\
\text { obesity [n(\%)] }\end{array}$ & 103(6.4) & $464(29.0)$ & $858(52.9)$ & $1241(76.2)$ & 1823.565 & 0.000 \\
\hline $\mathrm{SBP}(\mathrm{mmHg})$ & $124.05 \pm 9.79$ & $125.38 \pm 9.17$ & $125.99 \pm 8.59$ & $126.27 \pm 8.92$ & 18.890 & 0.000 \\
\hline $\mathrm{DBP}(\mathrm{mmHg})$ & $75.57 \pm 7.49$ & $76.08 \pm 7.19$ & $76.43 \pm 6.98$ & $76.47 \pm 7.30$ & 5.466 & 0.001 \\
\hline $\mathrm{FPG}(\mathrm{mmol} / \mathrm{L})$ & $5.30 \pm 1.53$ & $5.59 \pm 1.73$ & $5.76 \pm 1.74$ & $6.17 \pm 2.14$ & 67.125 & 0.000 \\
\hline TC (mmol/L) & $4.63 \pm 1.10$ & $4.83 \pm 1.22$ & $4.96 \pm 1.16$ & $5.13 \pm 1.13$ & 55.456 & 0.000 \\
\hline TG (mmol/L) & $0.80 \pm 0.28$ & $1.12 \pm 0.37$ & $1.46 \pm 0.44$ & $2.63 \pm 1.61$ & 1369.13 & 0.000 \\
\hline $\begin{array}{l}\text { Family history } \\
\text { of diabetes } \\
{[n(\%)]}\end{array}$ & $68(4.2)$ & 173(10.8) & $315(19.4)$ & $562(34.5)$ & 583.673 & 0.000 \\
\hline \multicolumn{7}{|c|}{ BMI, body mass index; WC, waist circumference; WHtR, waist-to-height ratio; } \\
\hline \multicolumn{7}{|c|}{ SBP, systolic blood pressure; DBP, diastolic blood pressure; } \\
\hline FPG, fasting pl & glucose; $\mathrm{T}$ & al cholest & G, triglyce & & & \\
\hline
\end{tabular}

The results of ROC curve analysis were shown in Table 3. LAP (AUC $=0.650 ; 95 \% \mathrm{Cl}=0.637$ to 0.662 ) was a better indicator than $\mathrm{BMI}(\mathrm{AUC}=0.579 ; 95 \% \mathrm{Cl}=0.566$ to 0.592$)$, WHtR (AUC $=0.537 ; 95 \% \mathrm{Cl}=0.524$ to 
0.550), WC (AUC=0.508; $95 \% \mathrm{Cl}=0.495$ to 0.521 ) to predict IFG and diabetes. The best cut-off value of LAP to predict IFG and diabetes was 33.54. It was found that LAP value could be used to diagnose IFG and diabetes risk (AUC=0.650; $P=0.007$ ). Sensitivity and specificity values for $B M I, W C, W H t R$ and LAP were shown in Figure 2.

Table 3

The comparison of obesity indexes in predicting IFG and diabetes risk

\begin{tabular}{|llllllll|}
\hline Variables & $\begin{array}{l}\text { Cut-off } \\
\text { value }\end{array}$ & $\begin{array}{l}\text { Sensitivity } \\
(\%)\end{array}$ & $\begin{array}{l}\text { Specificity } \\
(\%)\end{array}$ & $\begin{array}{l}\text { Youden } \\
\text { index }\end{array}$ & AUC (95\%Cl) & $Z$ & $P^{*}$ \\
\hline BMI & 25.14 & 48.86 & 64.96 & 0.138 & $\begin{array}{l}0.579(0.566- \\
0.592)\end{array}$ & 9.051 & $<0.001$ \\
\hline WC & 83.5 & 64.38 & 48.66 & 0.131 & $\begin{array}{l}0.508(0.495- \\
0.521)\end{array}$ & 13.947 & $<0.001$ \\
\hline WHtR & 0.53 & 51.53 & 59.85 & 0.114 & $\begin{array}{l}0.537(0.524- \\
0.550)\end{array}$ & 14.869 & $<0.001$ \\
\hline LAP & 33.54 & 54.60 & 62.42 & 0.170 & $\begin{array}{l}0.650(0.637- \\
0.662)\end{array}$ & - & - \\
\hline *: Compared with that of LAP. & & & & & & \\
\hline
\end{tabular}

The results of multinomial logistic regression analysis were conducted in Table 4. Subjects with the higher quartiles of LAP and family history were more likely to develop IFG and diabetes than those with the first quartile and non-family history. After controlling for confounders, the risk of IFG (adjusted OR: 2.735, 95\% Cl: 1.794-4.170) and diabetes (adjusted OR: 1.815, 95\% Cl: 1.297-2.541) significantly increased in subjects with the fourth quartile of LAP compared with the first quartile, meanwhile, increasing risk of diabetes (adjusted OR: $2.307,95 \% \mathrm{Cl}$ : 1.787-2.978) was observed in family history participants compared with those non-family history participants. 
Table 4

The logistic regression analysis of LAP and family history of diabetes with IFG and diabetes

\begin{tabular}{|c|c|c|c|c|c|c|}
\hline \multirow[t]{2}{*}{ Variables } & \multicolumn{2}{|c|}{ OR $(95 \% \mathrm{Cl})^{1}$} & \multicolumn{2}{|c|}{ OR $(95 \% \mathrm{Cl})^{2}$} & \multicolumn{2}{|c|}{ OR $(95 \% \mathrm{Cl})^{3}$} \\
\hline & IFG & Diabetes & IFG & Diabetes & IFG & Diabetes \\
\hline \multicolumn{7}{|c|}{ Quartiles of LAP } \\
\hline $\mathrm{Q}_{1}$ & 1.00 (ref.) & 1.00 (ref.) & 1.00 (ref.) & 1.00 (ref.) & 1.00 (ref.) & 1.00 (ref.) \\
\hline \multirow[t]{2}{*}{$\mathrm{Q}_{2}$} & 1.308 & $1.482^{\star \star}$ & $1.357^{*}$ & $1.545^{\star \star \star}$ & 1.327 & $1.421^{\star \star}$ \\
\hline & $\begin{array}{l}(0.987- \\
1.733)\end{array}$ & $\begin{array}{l}(1.181- \\
1.859)\end{array}$ & $\begin{array}{l}(1.021- \\
1.803)\end{array}$ & $\begin{array}{l}(1.230- \\
1.942)\end{array}$ & $\begin{array}{l}(0.980- \\
1.797)\end{array}$ & $\begin{array}{l}(1.115- \\
1.810)\end{array}$ \\
\hline \multirow[t]{2}{*}{$\mathrm{Q}_{3}$} & $2.151^{\star \star \star}$ & $1.680^{\star \star \star}$ & $2.244^{\star \star \star}$ & $1.778^{\star \star \star}$ & $2.211^{\star \star \star}$ & $1.526^{\star *}$ \\
\hline & $\begin{array}{l}(1.656- \\
2.793)\end{array}$ & $\begin{array}{l}(1.342- \\
2.103)\end{array}$ & $\begin{array}{l}(1.720- \\
2.927)\end{array}$ & $\begin{array}{l}(1.417- \\
2.232)\end{array}$ & $\begin{array}{l}(1.604- \\
3.046)\end{array}$ & $\begin{array}{l}(1.172- \\
1.988)\end{array}$ \\
\hline \multirow[t]{2}{*}{$\mathrm{Q}_{4}$} & $2.465^{\star \star \star}$ & $2.416^{\star \star \star}$ & $2.615^{\star \star \star}$ & $2.629^{\star \star \star}$ & $2.735^{\star \star \star}$ & $1.815^{\star *}$ \\
\hline & $\begin{array}{l}(1.891- \\
3.213)\end{array}$ & $\begin{array}{l}(1.939- \\
3.009)\end{array}$ & $\begin{array}{l}(1.991- \\
3.435)\end{array}$ & $\begin{array}{l}(2.097- \\
3.295)\end{array}$ & $\begin{array}{l}(1.794- \\
4.170)\end{array}$ & $\begin{array}{l}(1.297- \\
2.541)\end{array}$ \\
\hline \multicolumn{7}{|c|}{$\begin{array}{l}\text { Family history of } \\
\text { diabetes }\end{array}$} \\
\hline No & 1.00(ref.) & 1.00(ref.) & 1.00(ref.) & 1.00(ref.) & 1.00 (ref.) & 1.00 (ref.) \\
\hline \multirow[t]{2}{*}{ Yes } & $1.426^{\star \star}$ & $1.939^{\star \star \star}$ & $1.420^{\star \star}$ & $1.935^{\star \star \star}$ & 1.223 & $2.307^{\star \star \star}$ \\
\hline & $\begin{array}{l}(1.152- \\
1.766)\end{array}$ & $\begin{array}{l}(1.634- \\
2.302)\end{array}$ & $\begin{array}{l}(1.144- \\
1.761)\end{array}$ & $\begin{array}{l}(1.629- \\
2.298)\end{array}$ & $\begin{array}{l}(0.895- \\
1.672)\end{array}$ & $\begin{array}{l}(1.787- \\
2.978)\end{array}$ \\
\hline \multicolumn{7}{|c|}{ Family history of diabetes was defined as one parent or both parents having diabetes. } \\
\hline \multicolumn{7}{|c|}{${ }^{\star} P<0.05 ;{ }^{* \star} P<0.01 ;{ }^{\star \star \star} P<0.001$} \\
\hline \multicolumn{7}{|c|}{1 Unadjusted. } \\
\hline \multicolumn{7}{|c|}{${ }^{2}$ Adjusted for age, sex, educational level, marital status, physical activity, smoking and drinking. } \\
\hline
\end{tabular}

The interaction analysis results were presented in Table 5. The adjusted OR of individuals with the highest LAP and family history of diabetes $(2.820,95 \% \mathrm{Cl}$ : 2.362 to 3.368$)$ possessed the highest risk of getting IFG and diabetes as compared with the lowest LAP and non-family history subjects, the results of RERI (1.538, 95\%Cl: 0.167 to 3.612$)$, AP $(0.375,95 \% \mathrm{Cl}: 0.118$ to 0.631$)$ and SI $(1.980,95 \% \mathrm{Cl}: 1.206$ to 
3.251) indicated a significant interaction effect of LAP and family history of diabetes on IFG and diabetes. 
Table 5

The interaction analysis of LAP with family history of diabetes and obesity on risk of IFG and diabetes

\begin{tabular}{|c|c|c|c|c|c|c|}
\hline \multicolumn{2}{|c|}{ Variables } & \multirow[t]{2}{*}{ case/total } & \multirow[t]{2}{*}{$\mathrm{OR}^{2}(95 \% \mathrm{Cl})$} & \multicolumn{3}{|c|}{ Measures of interaction } \\
\hline & & & & RERI & AP & SI \\
\hline \multirow[t]{2}{*}{$\mathrm{LAP}^{1}$} & $\begin{array}{l}\text { Family history of } \\
\text { diabetes }\end{array}$ & & & & $0.375^{\star}$ & $1.980^{\star}$ \\
\hline & & & & $\begin{array}{l}(0.167- \\
3.612)\end{array}$ & $\begin{array}{l}(0.118- \\
0.631)\end{array}$ & $\begin{array}{l}(1.206- \\
3.251)\end{array}$ \\
\hline Low & No & $3453 / 3775$ & 1.00(ref.) & & & \\
\hline Low & Yes & $322 / 3775$ & $\begin{array}{l}1.898^{\star \star \star} \\
2.459)\end{array}$ & & & \\
\hline High & No & $1896 / 2692$ & $\begin{array}{l}1.566^{\star \star \star} \\
1.830)\end{array}(1.341-$ & & & \\
\hline High & Yes & $796 / 2692$ & $\begin{array}{l}2.820^{\star \star \star} \\
3.368)\end{array}(2.362-$ & & & \\
\hline \multirow[t]{2}{*}{$\mathrm{LAP}^{1}$} & General obesity & & & $1.221^{\#}$ & $0.245^{\#}$ & $1.453^{\#}$ \\
\hline & & & & $\begin{array}{l}(-0.183- \\
2.356)\end{array}$ & $\begin{array}{l}(-0.010- \\
0.476)\end{array}$ & $\begin{array}{l}(0.904- \\
2.357)\end{array}$ \\
\hline Low & No & $3555 / 3775$ & 1.00 (ref.) & & & \\
\hline Low & Yes & $220 / 3775$ & $\begin{array}{l}1.320(0.950- \\
1.833)\end{array}$ & & & \\
\hline High & No & $2064 / 2692$ & $\begin{array}{l}1.732^{\star \star \star} \\
2.009)\end{array}$ & & & \\
\hline High & Yes & $628 / 2692$ & $\begin{array}{l}2.202^{\star \star \star} \\
2.675)\end{array}$ & & & \\
\hline \multirow[t]{2}{*}{$\mathrm{LAP}^{1}$} & Abdominal obesity & & & $1.492^{*}$ & $0.413^{*}$ & $1.824^{\#}$ \\
\hline & & & & $\begin{array}{l}(0.087- \\
3.723)\end{array}$ & $\begin{array}{l}(0.014- \\
0.756)\end{array}$ & $\begin{array}{l}(0.873- \\
3.526)\end{array}$ \\
\hline Low & No & $2947 / 3775$ & 1.00(ref.) & & & \\
\hline Low & Yes & $828 / 3775$ & $\begin{array}{l}1.130(0.925- \\
1.382)\end{array}$ & & & \\
\hline
\end{tabular}

1: Grouped by the cut-off value (33.54) in Table 3.

2: Adjusted for age, sex, educational level, marital status, physical activity, smoking, drinking, SBP, $\mathrm{DBP}, \mathrm{TC}$ and TG.

${ }^{*} P<0.05 ;{ }^{\#} P>0.05$. 


\begin{tabular}{|c|c|c|c|c|c|c|}
\hline \multirow{2}{*}{\multicolumn{2}{|c|}{ Variables }} & \multirow[t]{2}{*}{ case/total } & \multirow[t]{2}{*}{$\mathrm{OR}^{2}(95 \% \mathrm{Cl})$} & \multicolumn{3}{|c|}{ Measures of interaction } \\
\hline & & & & RERI & AP & SI \\
\hline High & No & $854 / 2692$ & $\begin{array}{l}1.469^{\star \star \star} \\
1.803)\end{array}$ (1.197- & & & \\
\hline High & Yes & $1838 / 2692$ & $\begin{array}{l}1.997^{* \star \star} \\
2.315)\end{array}$ & & & \\
\hline \multicolumn{7}{|c|}{ 1: Grouped by the cut-off value (33.54) in Table 3.} \\
\hline \multicolumn{7}{|c|}{$\begin{array}{l}\text { 2: Adjusted for age, sex, educational level, marital status, physical activity, smoking, drinking, SBP } \\
\text { DBP, TC and TG. }\end{array}$} \\
\hline \multicolumn{7}{|c|}{${ }^{*} P<0.05 ;{ }^{\#} P>0.05}$. \\
\hline
\end{tabular}

However, no statistically significant interaction effects were found between LAP and general obesity, RERI was 1.221 (95\% Cl: -0.183 to 2.356$)$, AP was 0.245 (95\% Cl: -0.010 to 0.476$)$ and SI was 1.453 (95\% Cl: 0.904 to 2.357). Moreover, compared to individuals with low-LAP and non-abdominal obesity, the adjusted OR of subjects with high-LAP and abdominal obesity was 1.997 (95\% Cl: 1.722 to 2.315 ), however, the results of RERI $(1.492,95 \% \mathrm{Cl}: 0.087$ to 3.723$), A P(0.413,95 \% \mathrm{Cl}: 0.014$ to 0.756$)$ indicated a significant interaction of LAP and abdominal obesity, but the result of SI (1.824, 95\% Cl: 0.873 to 3.526$)$ did not.

\section{Discussion}

With the high prevalence of overweight and obesity, unhealthy dietary habits and sedentary lifestyles, IFG and diabetes is increasingly common among community residents, and has become an important public health issue [37-38]. The International Diabetes Federation has predicted that the number of individuals with diabetes will increase to 380 million in 2025 and 439 million in 2030 [39-40]. The prevalence of diabetes and IFG was $14.33 \%$ and $9.37 \%$ in this population- based survey, with other studies reported in China, the prevalence of diabetes was as high as $30.6 \%$ in Heilongjiang and $17.9 \%$ in Jilin, whereas in some provinces the prevalence was as low as 3.6\% in Yunnan and $5.9 \%$ in Zhejiang and $12.5 \%$ in Hunan [41]. Participants living in Jilin and Liaoning Province showed a relatively high prevalence $(11.8 \%$ and $16.5 \%$, respectively) of IFG compared to our study [42-43], we found that the prevalence in the whole country is imbalance in geographic areas, with a vast territory, China has a tremendous difference among different regions, the levels of economic development and lifestyles differences may influence the epidemic of IFG and diabetes.

In most population-based studies, BMI, WC, WHtR are the most common obesity indexes, but there are some limitations in using these indicators to diagnose obesity. Firstly, BMI has inherent inability to distinguish subcutaneous fat and visceral fat. Secondly, BMI does not characterize body fat distribution, which was known as a determinant metabolic risk, in this aspect, WC and WHtR might better represent 
visceral fat. Finally, although WC and WHtR can represent central obesity, they can not show the excess body fat in circulating blood. However, a new obesity index that can predict body fat simply and effectively is urgently needed. After the first introduce by Kahn [18] showed that LAP is an index of excessive lipid accumulation and perform better than BMI for recognizing diabetes risk, several studies revealed the association between LAP and cardiovascular risk over the past years [44-45]. LAP, a combination of WC and TG, can reflect visceral fat excess and has theoretical basis to evaluate visceral obesity [46]. In our study, we analyzed data from a community health management project, tried to investigate the relationship between LAP and IFG, diabetes, and compared LAP with BMI, WC, WHtR for diabetes diagnostic accuracy. The prevalence of IFG and diabetes gradually increased across LAP quartiles, the values in the fourth quartile of LAP were dramatically higher than in the first quartile $(12.6 \%$ vs. $5.9 \%, 20.8 \%$ vs. $8.9 \%$, respectively), and this conclusion was consistent with other similar studies in China. A cross-sectional study in Beijing showed that an elevated level of LAP was closely linked to an increased risk of diabetes in elderly people [47], and a survey in Anhui province confirmed that there is a positive correlation between LAP and IFG [48].

The results showed that the AUC of LAP (0.650) for predicting IFG and diabetes was higher than that of BMI (0.579), WHtR (0.537) and WC (0.508), indicating that LAP had more power for predicting IFG and diabetes compared with common obesity indexes. In addition, the identified cutoff value of LAP was 33.54 (sensitivity, $54.6 \%$; specificity, $62.42 \%$ ) in study population, a number of studies have found similar results. A study in northeastern Brail showed that the cutoff value of LAP index to present a higher chance of cardiovascular risk was 37.9 [49], an investigation conducted among Urumqi in China found that LAP was better than BMI to predict cardiovascular risk and the predictive accuracy was 38.41 in 215,651 adults [29]. Meanwhile, in southern Taiwan, China, Chiang et al [50] evaluated that the optimal cutoff value for the LAP index to predict diabetes was 28.4. There is still controversy about the optimal cutoff value of LAP to present cardiovascular risk, further studies with a large sample size stratified into age, sex and nutritional status categories (obesity or normal) are needed to investigate.

The interaction analysis in this study indicated that there was a significant interaction between LAP and family history of diabetes on the risk of IFG and diabetes, the etiology of diabetes is not well defined, but family history of diabetes has been considered a reflection of both genetic and environmental effects [51], and individuals with family history of diabetes are two to three times more likely to develop diabetes than those without family history individuals [52]. Similar reports reported the significant correlation between family history and risk of diabetes and IFG, a cross-sectional study in Sweden showed that family history of diabetes had an interactive influence on IFG in females [53]. An investigation conducted by Ustulin et al [54] proved a relevant significant association between family history of diabetes and risk of diabetes in middle-aged and elderly person. However, no significant interaction between LAP and general obesity was observed in study population. Previous studies have explored the interaction effect between LAP and abdominal obesity on risk of diabetes [48,55], but our result seem to be inconsistent. The results of RERI, AP indicated a significant interaction of LAP and abdominal obesity, but the result of SI did not. Abdominal obesity may result in increased blood glucose through some unknown 
mechanisms. So far, there are few surveys exploring the interaction of risk factors on IFG and diabetes risk, and the interactive mechanisms between LAP and other factors needs to be studied in the future.

There are some limitations in our study. First, as a cross-sectional study, the causal association between LAP and IFG, diabetes can not be determined. Secondly, we did not identify different cutoff values for LAP according to sex, age and nutritional status categories. Thirdly, the population of our study can not

fully represent the general population in the center of China. Finally, the enrolled individuals in this study were all middle-aged and elderly. So we suggest that additional longitudinal studies should evaluate in different sex and age groups, given that the association between LAP and IFG, diabetes risk is wellestablished.

\section{Conclusion}

In conclusion, LAP significantly associated with the IFG and diabetes risk and performed better than other obesity indices. Furthermore, LAP with family history of diabetes may have an interactive effect on the development of IFG and diabetes. Further studies should pay more attention to the gender and age differences of LAP and the mechanisms of interactive effect on IFG and diabetes risk.

\section{Abbreviations}

LAP: Lipid accumulation product; IFG: Impaired fasting glucose; BMI: Body mass index; WC: Waist circumference; WHtR: Waist to height ratio; ROC: Receiver operating characteristic; RERI: Relative excess risk of interaction; AP: Attributable proportion due to interaction; SI: Synergy index; SBP: Systolic blood pressure; DBP: Diastolic blood pressure; FPG: Fasting plasma glucose; TC: Total cholesterol; TG: Triglycerides; OR: Odds ratio; SD: Standard deviation; Cls: Confidence interval.

\section{Declarations}

\section{Ethics approval and consent to participate}

The study was supported by Bengbu Health Board and approved by the Ethics Committee of Bengbu Medical College. The procedure of this survey is in accordance with the principles of the 1983 Declaration of Helsinki. We are grateful to all professionals and participants.

\section{Consent for publication}

Not applicable.

\section{Availability of data and materials}

Data available within the article or its supplementary materials. 


\section{Competing interests}

The author declare that the research was conducted in the absence of any commercial or financial relationships that could be construed as a potential conflict of interest.

\section{Funding}

This study was financed by the National Science Foundation of China (number: 81703227), the "512" talent development program of Bengbu Medical College (number: by51202301), the Anhui Provincial Philosophy and Social Science Foundation (number: AHSKQ2018D49), the Research and Innovation Team of Bengbu Medical College (number: BYKC201901).

\section{Authors' contributions}

SL and ZYY designed the research. SL and SYQ drafted the manuscript. SYQ, JLL and ZJY collected the data. SL and SYQ performed the statistical analysis and interpreted the results. ZYY helped prepare the methods section. SL and JLL revised the manuscript critically. All authors read and approved the final manuscript.

\section{Acknowledgements}

We are grateful to all professionals and participants.

\section{Author details}

1 School of public health, Bengbu Medical College, Bengbu, Anhui Province, China,

2 Bengbu Health Board, Bengbu, Anhui Province, China

\section{References}

1. Whiting DR, Guariguata $L$, Weil C, et al. IDF diabetes atlas: global estimates of the prevalence of diabetes for 2011 and 2030. Diabetes Res Clin Pract. 2011;94(3):311-21.

2. International Diabetes Federation. IDF Diabetes Atlas. 8th ed. Brussels: International Diabetes Federation; 2017.

3. Fagg J, Valabhji J. How do we identify people at high risk of type 2 diabetes and help prevent the condition from developing? Diabet Med. 2019;36(3):316-25.

4. Laakso M. Biomarkers for type 2 diabetes. Mol Metab. 2019;27S(Suppl):139-46. 
5. Jensen PN, Fretts AM, Yu C, et al. Circulating sphingolipids, fasting glucose, and impaired fasting glucose: The strong heart family study. EBioMedicine. 2019;41:44-9.

6. Xu Y, Wang L, He J, et al. Prevalence and control of diabetes in Chinese adults. JAMA. 2013;310(9):948-59.

7. Gray N, Picone G, Sloan F, et al. Relation between BMI and diabetes mellitus and its complications among US older adults. South Med J. 2015;108(1):29-36.

8. Perkovic V, de Zeeuw D, Mahaffey KW, et al. Canagliflozin and renal outcomes in type 2 diabetes: results from the CANVAS Program randomised clinical trials. Lancet Diabetes Endocrinol. 2018;6(9):691-704.

9. Shi Z, Zhen S, Zimmet PZ, et al. Association of impaired fasting glucose, diabetes and dietary patterns with mortality: a 10-year follow-up cohort in Eastern China. Acta Diabetol. 2016;53(5):799806.

10. Zhan $\mathrm{Y}$, Sun $\mathrm{H}$, Wang B, et al. Impaired fasting glucose predicts the development of hypertension over 6 years in female adults: results from the rural Chinese cohort study. J Diabetes Complications. 2017;31(7):1090-5.

11. World Health Organization. Obesity and overweight. Available from: http://www.who.int/ newsroom/fact-sheets/detail/obesity-and-overweight. Accessed in 2018 (Jul 23).

12. Vieira JN, Braz MAD, Gomes FO, et al. Cardiovascular risk assessment using the lipid accumulation product index among primary healthcare users: a cross-sectional study. Sao Paulo Med J. 2019;137(2):126-31.

13. Biyik Z, Guney I. Lipid accumulation product and visceral adiposity index: two new indices to predict metabolic syndrome in chronic kidney disease. Eur Rev Med Pharmacol Sci. 2019;23(5):2167-73.

14. Jo A, Mainous AG 3rd. Information value of percent body fat with body mass index for the risk of abnormal blood glucose: a nationally representative cross-sectional study. BMJ Open. 2018;8(4):e019200.

15. Schulze MB, Heidemann C, Schienkiewitz A, et al. Comparison of anthropometric characteristics in predicting the incidence of type 2 diabetes in the EPIC-Potsdam study. Diabetes Care. 2006;29(8):1921-3.

16. Ching YK, Chin YS, Appukutty M, et al. Comparisons of conventional and novel anthropometric obesity indices to predict metabolic syndrome among vegetarians in Malaysia. Sci Rep. 2010;10(1):20861.

17. Ray L, Ravichandran K, Nanda SK. Comparison of lipid accumulation product index with body mass index and waist circumference as a predict of metabolic syndrome in Indian population. Metab Syndr Relat Disord. 2018;16(5):240-5.

18. Kahn HS. The "lipid accumulation product" performs better than the body mass index for recognizing cardiovascular risk: a population-based comparison. BMC Cardiovasc Disord. 2005;5:26.

19. Nascimento-Ferreira MV, Rendo-Urteaga T, Vilanova-Campelo RC, et al. Reply-letter to the editor-the lipid accumulation product is a powerful tool to predict metabolic syndrome in undiagnosed 
Brazilian adults. Clin Nutr. 2017;36(3):907-8.

20. Zhu HT, Yu M, Hu H, et al. Factors associated with glycemic control in community-dwelling elderly individuals with type 2 diabetes mellitus in Zhejiang, China: a cross-sectional study. BMC Endocr Disord. 2019;19(1):57.

21. Amini MR, Shahinfar H, Babaei N, et al. Association of dietary patterns with visceral adiposity, lipid accumulation product, and triglyceride-glucose index in Iranian adults. Clin Nutr Res. 2020;9(2):14556.

22. Lee JW, Lim NK, Park HY. The product of fasting plasma glucose and triglycerides improves risk prediction of type 2 diabetes in middle-aged Koreans. BMC Endocr Disord. 2018;18(1):33.

23. Lee JW, Lim NK, Park HY. The product of fasting glucose and triglycerides improves risk prediction of type 2 diabetes in middle-aged Koreans. BMC Endocr Disord. 2018;18(1):33.

24. de Oliveira CC, Roriz AKC, Ramos LB, et al. Indicators of adiposity predictors of metabolic syndrome in the elderly. Ann Nutr Metab. 2017;70(1):9-15.

25. Koo BK, Kim SW, Yi KH, et al. Changing relative contribution of abdominal obesity and a family history of diabetes on prevalence of diabetes mellitus in Korean men and women aged 30-49 years from 2001 to 2010. J Diabetes. 2015;7(4):465-72.

26. Choi J, Choi JY, Lee SA, et al. Association between family history of diabetes and clusters of adherence to healthy behaviors: cross-sectional results from the Health Examinees-Gem (HEXA-G) study. BMJ Open. 2019;9(6):e025477.

27. Imes CC, Lewis FM. Family history of cardiovascular disease, perceived cardiovascular disease risk, and health-related behavior: a review of the literature. J Cardiovasc Nurs. 2014;29(2):108-29.

28. Acheson LS, Wang C, Zyzanski SJ, et al. Family history and perceptions about risk and prevention for chronic diseases in primary care: a report from the family healthware impact trial. Genet Med. 2010;12(4):212-8.

29. Tian T, Pei H, Chen Z, et al. Comparison of lipid accumulation product and body mass index as indicators of diabetes diagnosis among 215,651 Chinese adults. Peer J. 2020;8:e8483.

30. Andersson T, Alfredsson L, Källberg H, et al. Calculating measures of biological interaction. Eur $\mathrm{J}$ Epidemiol. 2005;20(7):575-9.

31. Chen C, Lu FC, Department of Disease Control Ministry of Health, PR China. The guidelines for prevention and control of overweight and obesity in Chinese adults. Biomed Environ Sci. 2004;Suppl:1-36.

32. Zhai Y, Zhao W, Chen C. Verification on the cut-offs of waist circumference for defining central obesity in Chinese elderly and tall adults. Zhonghua Liu Xing Bing Xue Za Zhi. 2010;31(6):621-5. (Article in Chinese).

33. Browning LM, Hsieh SD, Ashwell M. A systematic review of waist-to-height ratio as a screening tool for the prediction of cardiovascular disease and diabetes: 0.5 could be a suitable global boundary value. Nutr Res Rev. 2010;23(2):247-69. 
34. Liu L, Writing Group of 2010 Chinese Guidelines for the Management of Hypertension. 2010 Chinese guidelines for the management of hypertension. Zhonghua Xin Xue Guan Bing Za Zhi. 2011;39(7):579-615. (Article in Chinese).

35. Lian F, Ni Q, Shen Y, et al. International traditional Chinese medicine guideline for diagnostic and treatment principles of diabetes. Ann Palliat Med. 2020;9(4):2237-50.

36. Knol MJ, VanderWeele TJ, Groenwold RHH, et al. Estimating measures of interaction on an additive scale for preventive exposures. Eur J Epidemiol. 2011;26(6):433-8.

37. Zhang F, Wan Q, Cao H, et al. Identical anthropometric characteristics of impaired fasting glucose combined with impaired glucose tolerance and newly diagnosed type 2 diabetes: anthropometric indicators to predict hyperglycaemia in a community-based prospective cohort study in southwest China. BMJ Open. 2018;8(5):e019735.

38. Zhang X, Meng X, Wang Y, et al. Six-year follow-up study on the association between white blood cell count and fasting blood glucose level in Chinese adults: A community-based health examination survey. Diabetes Metab Res Rev. 2019;35(4):e3125.

39. Shaw JE, Sicree RA, Zimmet PZ. Global estimates of the prevalence of diabetes for 2010 and 2030. Diabetes Res Clin Pract. 2010;87(1):4-14.

40. Yang L, Shao J, Bian Y, et al. Prevalence of type 2 diabetes mellitus among inland residents in China (2000-2014): A meta-analysis. J Diabetes Investig. 2016;7(6):845-52.

41. Zuo H, Shi Z, Hussain A. Prevalence, trends and risk factors for the diabetes epidemic in China: a systematic review and meta-analysis. Diabetes Res Clin Pract. 2014;104(1):63-72.

42. Zhao Q, Zhen Q, Li Y, et al. Prevalence and risk factors of impaired fasting glucose among adults in Northeast China: a cross-sectional study. Endocr Pract. 2018;24(7):677-83.

43. Yu S, Sun Z, Zheng L, et al. Prevalence of diabetes and impaired fasting glucose in hypertensive adults in rural China: far from leveling-off. Int J Environ Res Public Health. 2015;12(11):14764-79.

44. Ayundini G, Astrella C, Tahapary D, et al. A systematic review on the association between lipid accumulation product index and type 2 diabetes mellitus. J Asean Fed Endocr Soc. 2019;34(1):1620.

45. Dai D, Chang Y, Chen Y, et al. Visceral adiposity index and lipid accumulation product index: two alternate body indices to identify chronic kidney disease among the rural population in northeast China. Int J Environ Res Public Health. 2016;13(12):1231.

46. Li R, Li Q, Cui M, et al. Visceral adiposity index, lipid accumulation product and intracranial atherosclerotic stenosis in middle-aged and elderly Chinese. Sci Rep. 2017;7(1):7951.

47. Shen YY, Chen JC, Li G, et al. Relationship of lipid accumulation product with hypertension and diabetes among Beijing residents study. Zhonghua Yu Fang Yi Xue Za Zhi. 2017;51(5):415-20. (Article in Chinese).

48. Song J, Chen X, Jiang Y, et al. Association and interaction analysis of lipid accumulation product with impaired fasting glucose risk: a cross-sectional survey. J Diabetes Res. 2019;28:9014698. 
49. Vieira JN, Braz MAD, Gomes FO, et al. Cardiovascular risk assessment using the lipid accumulation product index among primary healthcare users: a cross-sectional study. Sao Paulo Med J. 2019;137(2):126-31.

50. Chiang JK, Koo M. Lipid accumulation product: a simple and accurate index for predicting metabolic syndrome in Taiwanese people aged 50 and over. BMC Cardiovasc Disord. 2012;12:78.

51. Xiong XF, Wei L, Xiao Y, et al. Family history of diabetes is associated with diabetic foot complications in type 2 diabetes. Sci Rep. 2020;10(1):17056.

52. Yuan $Y, X i e H$, Sun L, et al. A novel indicator of children's lipid accumulation product associated with impaired fasting glucose in Chinese children and adolescents. Diabetes Metab Syndr Obes. 2020;13:1653-60.

53. Hilding A, Eriksson AK, Agardh EE, et al. The impact of family history of diabetes and lifestyle factors on abnormal glucose regulation in middle-aged Swedish men and women. Diabetologia. 2006;49(11):2589-98.

54. Ustulin M, Rhee SY, Chon S, et al. Importance of family history of diabetes in computing a diabetes risk score in Korean prediabetic population. Sci Rep. 2018;8(1):15958.

55. Luo W, Guo Z, Wu M, et al. Interaction of smoking and obesity on type 2 diabetes risk in a Chinese cohort. Physiol Behav. 2015;139:240-3.

\section{Figures}




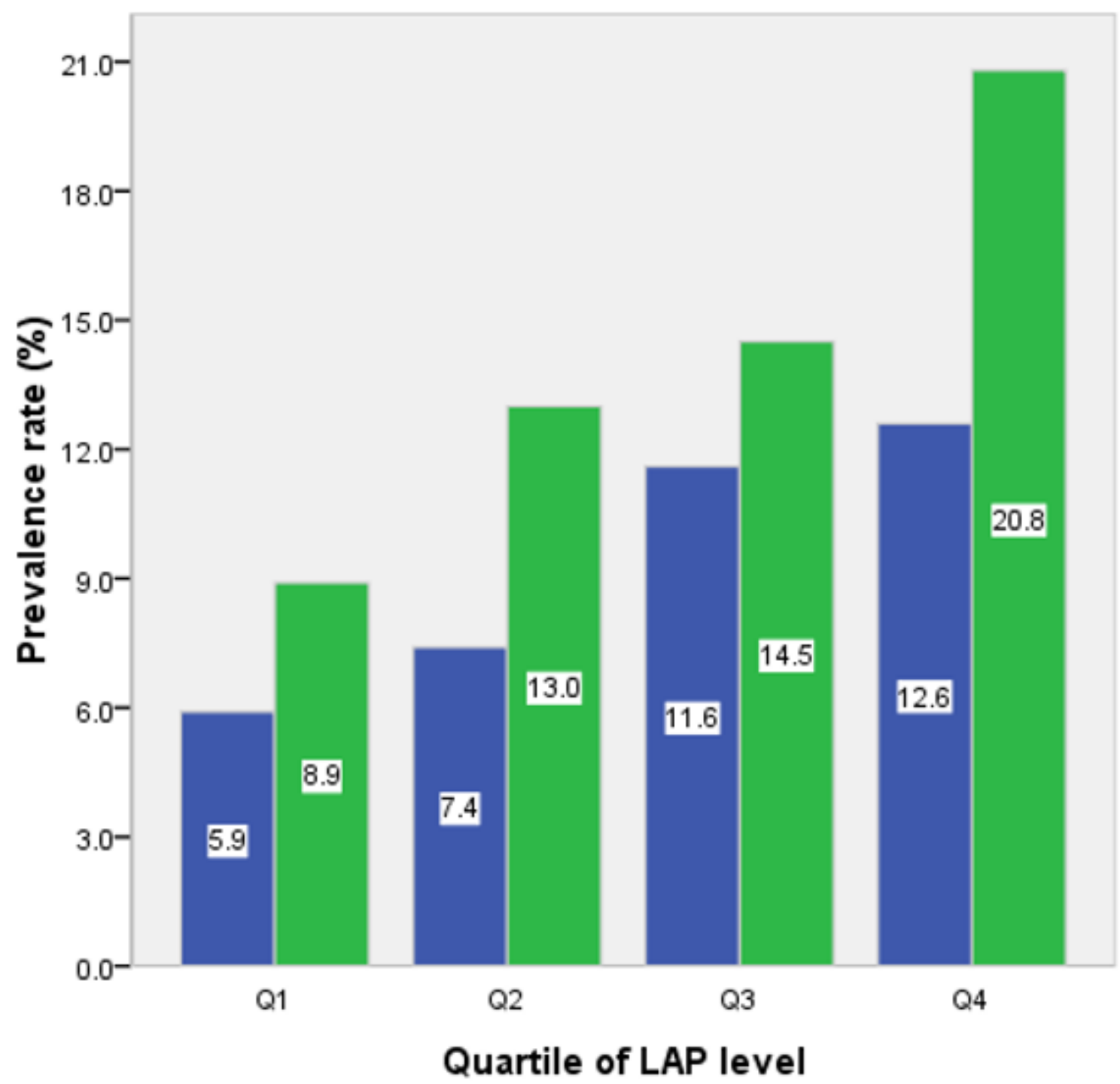

Figure 1

Prevalence of IFG and diabetes in different LAP quartiles ( $P$ for trend $<0.001$ for IFG and diabetes groups) $\left(Q_{1}:<18.17 ; Q_{2}: 18.17\right.$ to $28.79 ; Q_{3}: 28.80$ to $\left.46.19 ; Q_{4}: \geq 46.20\right)$. 


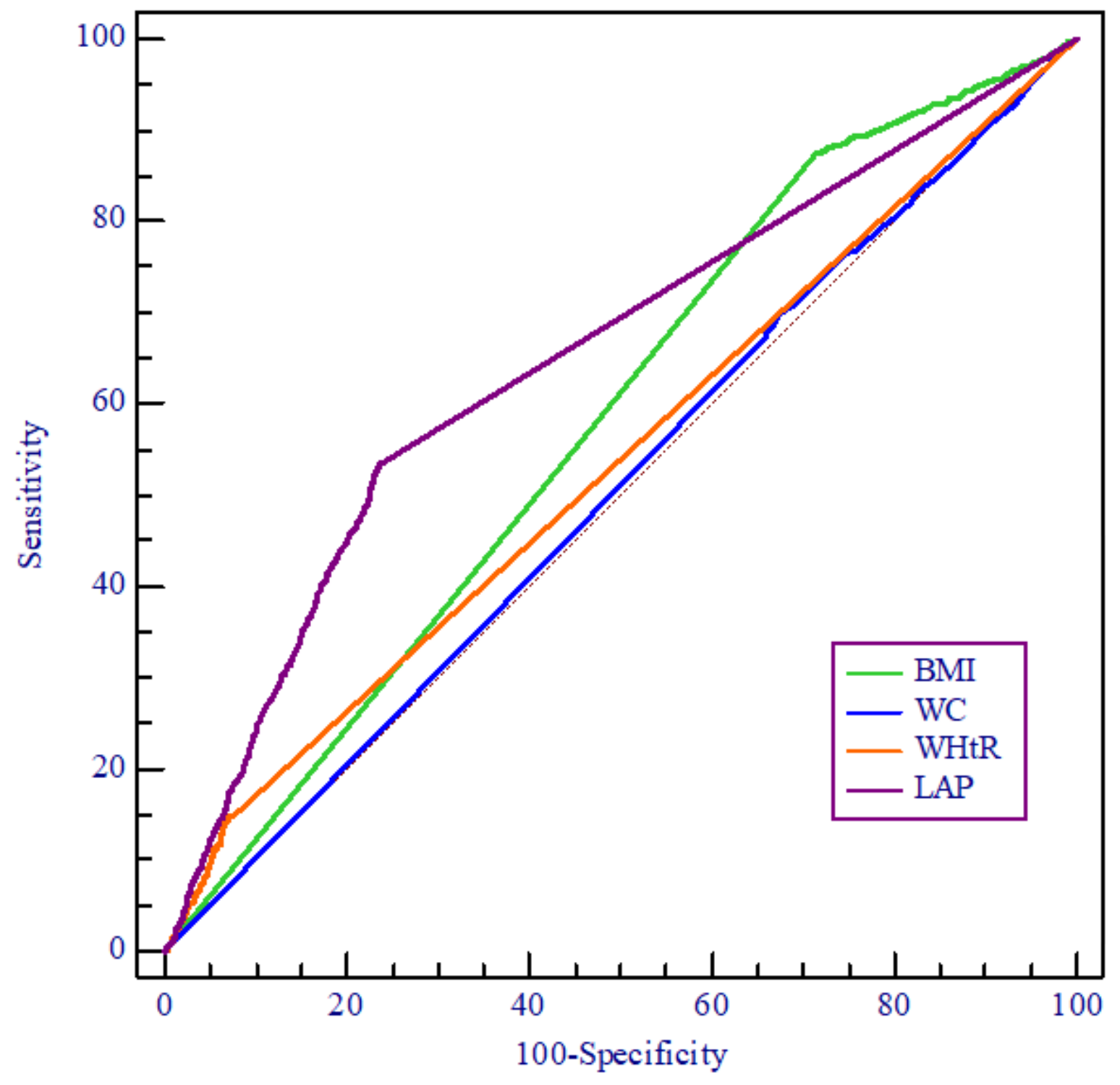

Figure 2

The ROC curve of different obesity indexes in predicting IFG and diabetes risk.

\section{Supplementary Files}

This is a list of supplementary files associated with this preprint. Click to download.

- data.sav 